\title{
Reinserção social da população do cárcere e suas expectativas no projeto Olimpo em Belém do Pará
}

\section{Social reinsertion of the prison population and expectations of prisoners: the case of the project olympus in Belém}

Soliane Fernandes Guimarães - Especialista em Gestão Penitenciária pela FAP, Diretora da Escola de Administração Penitenciária do Pará (EAP/SUSIPE). E-mail: solianefernandes@hotmail.com.

Wilson José Barp - Doutor em Ciências Sociais pela Universidade Estadual de Campinas. Atualmente é adjunto da Universidade Federal do Pará. E-mail: wbarp@uol.com.br

Fernanda Valli Nummer - Doutora em Antropologia Social pela Universidade Federal do Rio Grande do Sul. Pesquisadora e professora da Universidade Federal do Pará. E-mail: fernandanummer@gmail.com

\section{Resumo}

O Sistema Penitenciário Brasileiro atual vive uma realidade bastante complexa. Deste modo, desenvolver este trabalho possibilitou uma investigação científica sobre os desafios dos projetos de reinserção social da população do cárcere e as expectativas dos presos que participam do projeto OLIMPO, já que esse trabalho teve como objetivo avaliar qual a percepção dos presos que participam das atividades laborais implementadas pelo sistema carcerário, quando do cumprimento de suas Penas. A Pesquisa baseou-se na metodologia qualitativa, utilizando a técnica do grupo focal. Entre os seus resultados, detectaram-se aspectos referentes ao perfil dos presos envolvidos no projeto, bem como a grande satisfação destes em participarem de programas voltados para atividades laborais, esclarecendo, assim, que o trabalho para os presos no sistema penitenciário está relacionado principalmente ao direito à remição de pena e aos privilégios ofertados intramuros, como saídas diárias ao trabalho, possibilidade de visita aos familiares e amigos.

\section{Palavras-chave}

Sistema prisional. Trabalho. Reinserção social. Controle social.

\begin{abstract}
The Brazilian Penitentiary System today live a very complex reality. Thus, this study has helped to develop a scientific research project on the challenges of social reintegration of the prison population and expectations of prisoners participating in the OLYMPUS project, since this work was to evaluate the perception of the inmates who participate in activities labor implemented by the prison system, when the fulfillment of their feathers. The research was based on qualitative methodology, using the focus group technique. Among their results was detected aspects relating to the profile of the inmates involved in the project, as well as the great pleasure of participating in these programs to work activities, thereby clarifying that the synonym of work for prisoners in the prison system is mainly related to right to redemption penalty and privileges offered intramural such as daily work outs, possibility to visit relatives and friends.
\end{abstract}

\section{Keywords}

Prison system. Work. Social reintegration. Social control. 


\section{ASPECTOS SOBRE O DESAFIO DA REINSERÇÃO SOCIAL}

Ao tratar dos paradigmas que envolvem os aspectos da Reinserção, fazse necessário compreender que tal termo é usado tanto por operadores do sistema prisional quanto por estudiosos com outras grafias. As mais comuns são: Recuperação, Reintegração e Inserção Social. Tais termos possuem o mesmo significado quando do resultado que se espera do processo de custódia do homem encarcerado, que, de acordo com a Lei de Execução Penal, em seu art. 1..$^{\circ}$ institui que "a execução penal tem por objetivo efetivar as disposições de sentença ou decisão criminal e proporcionar condições para a harmônica integração social do condenado e do internado" (grifo nosso). De acordo com Krahn (2012, p. 15), ressocialização tem vários conceitos, "[...] alguns ainda acreditam na reinserção como uma emenda, onde a pessoa é presa para cumprir uma penitência, e a redenção é o que se espera do cumprimento da pena".

Para Krahn (2012, p.6), "A ressocialização, reintegração social, regeneração, tratamento do indivíduo criminoso acaba se transformando em um dos objetivos principais da pena privativa de liberdade". Assim, falar sobre todos estes conceitos impele-se para um resultado que deve ser alcançado pelo sistema penitenciário, durante e após o processo de prisão. Trata-se, portanto, de proporcionar aos presos meios eficazes para sair do cárcere melhores do que entraram, isto é, envolve a responsabilidade do Estado em proporcionar instrumentos que façam daquele indivíduo ora criminoso, alguém que possa viver harmoniosamente em sociedade, usufruindo dos frutos de sua competência moral e ética, agindo corretamente de acordo com os preceitos sociais, morais e legais. Para Nunes (2012, p. 44), "[...] o conceito de ressocialização de detentos, pelo trabalho e pela qualificação profissional, com o propósito de prepará-los ao reingresso social, baseia-se na afirmação de que o trabalho é fonte de equilíbrio na nossa sociedade".

Para Moreira (2007, p. 256), "a ressocialização do condenado se assenta em dois elementos essenciais: a Assistência e o Trabalho". De fato, é o que determina a Lei de Execução Penal e outras normativas relacionadas a esta área, como as Regras Mínimas para Tratamento do Preso no Brasil, conforme mais bem detalhado adiante neste trabalho. Moreira (2007, p. 258-9) ainda complementa, afirmando que ressocializar significa “... mudar a maneira de ser de um condenado, conformando o seu comportamento às normas socialmente instituídas, a partir da internalização dos valores, crenças e maneiras de perceber o mundo que são definidas pela instituição penal".

Embora existam pressupostos legais e normativos que tratam das políticas de reinserção social, a realidade existente não consegue atender os 
ideais preconizados nas diretrizes institucionais. O desejo de fazer as coisas acontecerem faz com que tais políticas sejam efetivadas de forma superficial, pois o que se vê, de modo geral, no sistema penitenciário brasileiro, na prática, são atividades incoerentes com as exigências socioeconômicas do lado de fora da Cadeia, pois conforme Santos (2001, p.32), “[...] o argumento é sempre o mesmo: não há verba. No fundo, o que parece é haver uma desconfiança nesses métodos humanitários que pregam a solução dos problemas pelo ataque às suas causas".

Segundo destacado por Cavalcante Jr. (2004, p. 31), “a Lei de Execuções Penais vem proclamando a busca pelos ideais de recuperação dos criminosos”. Para Nunes (2012, p. 13), “[...] o indivíduo durante o cumprimento de sua pena deve ter acesso aos meios que possibilitem a sua reeducação, garantindo assim a sua readaptação ao convívio social ao final do término de pena”.

Vale ressaltar que, além da insuficiência de pessoal para atuar na linha de frente do sistema penitenciário, há um conflito entre os técnicos (profissionais de tratamento) e os agentes penitenciários.

O fracasso de um estabelecimento carcerário, quanto ao alvo de reeducação, seja no Brasil, nos Estados Unidos, na Inglaterra ou na Noruega, é atribuído, indefectivelmente, em sua maior parte, ao número deficiente de profissionais de tratamento (médicos, psicólogos, educadores, assistentes sociais) e à imperfeita instrução da guarda, no sentido de se preocupar mais em ajudar o preso a se reabilitar do que em cuidar da segurança e disciplina do estabelecimento. (THOMPSON 2002, p. 17)

Porém, na fala dos técnicos, os agentes dificultam o processo, pois justificam escassez de servidores suficientes, equipamentos insuficientes, como algema para realizar o deslocamento do preso de um espaço para o outro; por sua vez, os agentes se queixam de que o técnico quer "aparecer", quer se intrometer na segurança. É um impasse de longas datas, mas que reflete uma realidade vivenciada em todo sistema penitenciário brasileiro. Uma das situações que levam a esse conflito deve estar relacionada com os fins propostos à prisão, que ora se trata de um espaço de confinamento, de punição, ora se revela como um espaço capaz de transformar a vida do indivíduo, e, nesta lógica, isso é repassado ao corpo funcional, embora inconscientemente, como se um (agente penitenciário) representasse a punibilidade e o outro (técnicos) o tratamento, conforme pode ser visualizado por Thompson (2002, p. 41), a saber, “[...] a penitenciária deve 1) punir, 2) intimidar, 3) regenerar. Espera-se do guarda, por conseguinte: fazer os presos sofrerem (metas 1 e 2), e procurar ser amigo do interno, lidando com ele como se fosse um paciente ou aluno (meta 3)". 
Portanto, há de se buscar formas de se minimizar tal problemática pelo fato de que não existe outra forma de trabalhar a reinserção dos presos, senão com o auxílio dos agentes e de todos os que compõem o corpo funcional do Sistema Penitenciário. Pode ser o projeto mais assertivo, com disponibilidade de recursos, mas, se não tiver o apoio das pessoas envolvidas no processo, o resultado será um desastre.

Nesse sentido, Krahn (2012, p. 17) reforça essa visão afirmando que a participação dos agentes penitenciários no processo de reinserção social é indispensável: “[...] os agentes penitenciários, estes responsáveis principalmente pela segurança e os que observam diariamente os internos nos módulos, são os que podem dar o aval principal para a participação de um interno em determinada atividade".

Como se percebe, aplicar o que está preconizado nas leis não tem sido tarefa fácil para o Sistema Penitenciário. Ouve-se sempre falar sobre as dificuldades enfrentadas pelo professor no processo de educação formal de uma criança ou de um jovem numa escola de ensino fundamental ou médio, imagine o desafio de se trabalhar o processo de reinserção do homem privado de liberdade, no contexto da realidade brasileira atual, com suas mazelas e deficiências. Conforme Mesquita (2009, p. 33), “[...] as penitenciárias brasileiras não têm cumprido sua função ressocializadora [...]. O Estado brasileiro está torturando presos e extinguindo a possibilidade de voltarem 'recuperados' à sociedade".

Portanto, à luz do que foi ressalvado até o momento, destaca-se que a realidade enfrentada pelo sistema penitenciário brasileiro não permite que as políticas de reinserção social sejam priorizadas, pois o sistema prisional acaba tendo como função principal a punição e, neste sentido, quase que integralmente, o recurso a ele destinado é para suprir as excessivas demandas da área da segurança, que vai desde a construção de presídios, compra de materiais como algemas, cadeados, tonfas, equipamentos eletrônicos de revistas, restando para as ações de reinserção social ou que possuem este ideal, recursos minimamente irrisórios, com projetos não audaciosos, com poucos resultados efetivos na inclusão do homem preso no mundo exterior.

\section{REALIDADE DO SISTEMA PENITENCIÁRIO}

Segundo dados do Departamento Penitenciário Nacional/Ministério da Justiça, de dezembro de $2012^{1}$, a população carcerária brasileira é de 548.003 presos para 310.687 vagas divididas em 1.478 estabelecimentos prisionais. Esses dados

Site www. mj.gov.br/depen, pesquisado em 31/01/14.

Novos Cadernos NAEA • v. 20 n. $1 \cdot$ p. 213-230 • jan-abr 2017 
representam um dos principais problemas do Sistema Penitenciário Brasileiro, que é a superpopulação carcerária, que, segundo as observações de Melo et al. (2014, p.141), “[...] proporciona um ambiente insalubre físico, mental e social, pedagogicamente falando. A ausência da dignidade da pena desumaniza ainda mais o indivíduo, gerando agressividade, violência e insensibilidade afetivo-emocional."

O Estado do Pará acompanha esta mesma realidade, possuindo em torno de 7.889 vagas para uma população carcerária que gira em torno de 11.718 vagas distribuídas em 42 unidades prisionais, segundo dados do Núcleo de Administração Penitenciária da Susipe, de 17 de setembro de 2014. Isto representa um excedente populacional de 48,54\%, incluindo toda a população carcerária do Estado. Porém, quando se analisa separadamente as unidades localizadas na Capital/Região Metropolitana e Interior do Estado, tem-se, respectivamente, $38,66 \%$ e $65,66 \%$ de excedente populacional, dados estes noticiadores de que as condições de custódia para os presos das unidades dos interiores são piores que as da capital/área metropolitana.

Dessa forma, observa-se que o Sistema Penitenciário tem como preocupação maior o aumento de vagas, construção de novas unidades prisionais, bem como atender as demandas do encarceramento quanto às providências de recursos materiais, como algemas, alimentação, viaturas para atender audiências judiciais. Para Melo et al. (2014, p.142 ), “[...] a prisão, nos moldes atuais, é a mais cruel realidade brasileira, é um meio de degeneração total do ser humano e não um meio educativo como considera, tão brilhantemente, a Lei de Execução Penal.”

Cumpre esclarecer que os crescentes índices da criminalidade, bem como o da reincidência criminal no Brasil demonstram que as ações dentro das unidades penais são explicitamente ineficazes, devido a muitos problemas, que vão desde a infraestrutura inadequada até o aspecto de servidores em quantidade insuficiente e com precária formação profissional.

A partir desse contexto, na atual conjuntura do sistema penitenciário, idealizar a prisão como uma instituição de reinserção social não deixa de ser desafiador, pois, como foi visto, a realidade mostra que a prisão configura-se como um espaço de neutralização dos criminosos da sociedade, de segregação total. Salla (2006, p. 293) problematiza ainda mais a questão quando diz que "[...] boa parte da vida carcerária nas prisões brasileiras é controlada pelo próprios presos, como as celas em que irão habitar os recém-chegados, que tarefas realizarão ali, nos pavilhões ou mesmo em oficinas de trabalho".

Sendo assim, a situação descrita acima revela uma realidade existente no Brasil: o Estado sem poder de controle sobre a população carcerária, a prisão sendo comandada pelos próprios presos, os quais, internamente, definem 
ordens e meios de convivência, distribuem tarefas entre si, cometem novos crimes, etc. É o que Thompson (2002, p. 108) chama de "IRRECUPERAÇÃO PENITENCIÁRIA".

\section{PRISÃO COMO CONTROLE SOCIAL DO ESTADO}

Embora a prisão não resolva o problema da criminalidade, salvo os casos mais graves, a sociedade clama por mais ação do Estado em conter o transgressor atrás das grades.

E nessa perspectiva, o problema tende a piorar, já que a cadeia funciona como uma escola profissional para que os homens presos possam seguir na carreira, pois muitos entram por terem roubado uma galinha, uma lata de leite e saem assaltantes profissionais de banco, por exemplo.

Nessa percepção, a prisão é percebida como forma de controle social, que serve para segregar e excluir o pobre do circuito da sociedade, sendo que para Melossi e Pavarini (2006, p. 186) "foi na tentativa de resolver este problema que a fantasia reformadora do jovem Estado americano encontrou, na política do controle social, sua 'invenção' mais original: a penitenciária (penitentiary system)".

Assim, é importante esclarecer que hodiernamente o público que vive no sistema penitenciário tem algumas características comuns: em sua maioria são pessoas pobres, jovens, oriundas de famílias fragilizadas, sem formação escolar, não possuem qualificação profissional, possuem valores sociais distorcidos e, por isso, acabam se profissionalizando no crime ao entrarem nas prisões. Segundo Cavalcante Jr (2004, p. 71), “[...] no caso geral do Pará, vê-se que a população encarcerada nas prisões tem perfil também jovem [...] a população jovem que se envolve na criminalidade e é encerrada na prisão tem mais chances de voltar ao mundo do crime do que do trabalho".

Porém, para Cabral e Silva (2010, p. 158-9), esse desafio se torna difícil pelo fato de que a maioria dos projetos de reinserção voltados para atividades laborais, com utilização da mão de obra carcerária, tem se "caracterizado, entre outros aspectos, pelo pagamento irrisório e desrespeito às normas de segurança e higiene do trabalho, de modo que o trabalho acaba tendo, muitas vezes, o caráter de sanção e não de reinserção social".

Observa-se que os investimentos maiores do governo nessa área se concentram em remediar a questão da superlotação com a construção de novos presídios, sobrando para ações que poderiam efetivamente proporcionar ao apenado mudança e reflexão sobre suas condutas sociais muito pouco. 
Esse contexto reforça a ideia de prisão como um ambiente puramente de controle social, no qual sua missão se revela como espaços de neutralização, punição e segregação de criminosos do meio social, especialmente daqueles que vivem à margem da sociedade, se considerarmos a nova ordem econômica e social vigente.

Para Cavalcante Jr. (2004, p. 13), “a prisão seria uma instituição especial capaz de confinar os membros mais visíveis das multidões perigosas". Nesta lógica, fica evidente a quem se destina a prisão: às pessoas que andam fora da lei, desprovidas de meios e recursos financeiros; enquanto os grandes traficantes, os que realmente financiam o crime, ficam livres, sem qualquer restrição legal ou social.

Da mesma forma, Wacquant (2004, p. 1) enfatiza que a prisão funciona como um aparelho do Estado para controle social, quando observa que ela funciona como "um aspirador social para limpar a escória resultante das transformações econômicas em andamento e para eliminar do espaço público o refugo da sociedade de mercado".

Assim, nota-se que como forma de combater o aumento do crime e a reincidência criminal, a prisão passou a ser utilizada como campo de controle do crime, como espaço de segregação dos setores perigosos da população.

Nesse sentido, é possível perceber que, segundo Dias (2014, p. 113), “a condenação à pena de prisão é apenas a porta de entrada para um universo social em que a punitividade é a característica central". Embora haja uma serie de pressupostos legais que preconizam a efetividade de ações voltadas não apenas para a custódia dos presos, mas também para a reinserção social destes, verificase que a dinâmica trilhada dia após dia no cárcere é recheada por atitudes e luta de poder, seja entre os próprios presos ou entre esses e os servidores penitenciários.

Sendo assim, observa-se que não foi a estrutura da prisão que mudou, mas suas diretrizes em relação ao homem encarcerado, pois, para Santana (2012, p. 26), as prisões são "instituições feitas para regular o indivíduo". A prisão jamais pode ser confundida com um hospital ou uma escola; ela é um espaço de punição, de segregação em sua essência. Para Julião (2011, p. 143),

“[...] é conflituoso [...], o discurso predominante sobre o papel do sistema penitenciário como instituição de controle social no mundo moderno, onde se prima pela valorização discursiva de uma proposta de ressocialização do apenado, cuja práxis contraria tal discurso".

Os pressupostos brasileiros que tratam sobre as diretrizes da execução penal, atribuem à prisão a função de proporcionar condições para a harmônica integração social do apenado. Isto quer dizer que da prisão é exigido que, além da custódia, 
ainda contribua com ações sociais que melhorem sua conduta perante a sociedade. Porém, para Nunes (2012, p.29), "na prisão, não se recupera ninguém, os poucos que se recuperam e não voltam a cometer crimes, é devido a uma base familiar sólida, pois não é só o sentenciado que cumpre a pena, mas todos ao seu redor”.

É interessante que Thompson (2002, p. 10) questiona e ao mesmo tempo responde a uma inquietação que paira na mente de muitas pessoas: "alguém já conseguiu fazer prisão punitiva ser reformativa? - a experiência penitenciária, de mais de cento e cinquenta anos, responde: não, em nenhuma época, em nenhum lugar".

\section{A PRISÃO COMO UMA INSTITUIÇÃO TOTAL}

Vale destacar alguns preceitos levantados por Erving Goffman (1961, p. 11) ao enfatizar a prisão como uma instituição total, ou seja,

"um local de residência e trabalho onde um grande número de indivíduos com situação semelhante, separados da sociedade mais ampla por considerável período de tempo, levam uma vida fechada e formalmente administrada".

Partindo desse conceito, as prisões bem se enquadram na definição acima destacada, haja vista que todos que se encontram presos estão segregados da sociedade por algum ato cometido contra esta, por um longo período de tempo, tendo suas vidas "administradas" pelo estado. Neste caso, a prisão funciona como um espaço de proteção da sociedade, livrando-a de perigosos transgressores, como homicidas, estupradores, latrocidas, ladrões, assaltantes, traficantes, maníacos, etc.

Nesse sentido, muitas atribuições são dadas à prisão, enquadrando-a nos pressupostos de uma instituição total, tendo como fim específico e talvez mais importante o de mudar pessoas, conforme destacado por Goffman (1962, p.22): "são as estufas para mudar pessoas; cada uma é um experimento natural sobre o que se pode fazer ao eu".

Destaca-se, assim, um dos apontamentos verificados por Goffman (1961), quando analisou o funcionamento de uma instituição total, a qual trata da questão do tratamento igual para todos. No caso das prisões, independentemente do crime praticado, o Estado age com todos da mesma forma; os materiais dados para um são os mesmos que serão dados para o outro. Às vezes, um material que é usado por um é usado pelo outro ou outros, por exemplo, “[...] o material da instituição dado como substituto para aquilo que foi retirado é geralmente de um 
tipo "barato", mal ajustado, muitas vezes velho e igual para as amplas categorias de internados" (GOFFMAN, 1961, p. 29).

Nesse sentido, é manifesto que nessa lógica precária instalada, não apenas nos recursos materiais, mas também nas relações sociais, depara-se com aspectos degradantes vivenciados no interior dessas instituições, começando pela perda da identidade do detento, da sobrevivência em meio à violência no cárcere, além da falta de privacidade em todos os âmbitos de sua vida, especialmente no que se refere às necessidades fisiológicas, já que atualmente a situação do espaço físico nas prisões é algo bastante disputado, por conta da tão problemática superlotação.

Partindo desse contexto, obrigatoriamente, viver em coletividade não é uma questão de escolha, pois "o seu eu é sistematicamente, embora muitas vezes não intencionalmente, mortificado” (GOFFMAN, 1961, p.24).

\section{TRABALHO NO SISTEMA PENITENCIÁRIO E SUAS IMPLICAÇÕES}

Segundo as Regras Mínimas para Tratamento do Preso no Brasil, na oferta de trabalho ${ }^{2}$ devem ser consideradas as necessidades futuras do condenado, bem como as oportunidades oferecidas pelo mercado de trabalho.

É evidente que após o cumprimento da pena, a inserção no mundo do trabalho será um grande desafio para os ex-detentos, levando em consideração todas as complexidades que envolvem o currículo desse cidadão, bem como todas as transformações e exigências que compõem essa nova conjuntura social. $\mathrm{Na}$ concepção de Antunes e Alves (2004, p. 336), o trabalho e a classe trabalhadora apresentam-se com novas formatações, os trabalhadores estáveis vêm dando lugar a um novo proletário fabril e de serviço, cuja característica principal é a precarização do trabalho e de suas condições, por meio de empregos informais.

Vale salientar que alguns aspectos característicos do mundo do trabalho atual têm dificultado a inserção de uma grande parcela da sociedade neste âmbito, deixando excluídos jovens, idosos e muitos em plena força produtiva, incluindo entre esses os egressos do sistema penitenciário, conforme enfatizado por Antunes e Alves (2004, p. 339), quando diz que "[...] outra tendência presente no mundo do trabalho é a crescente exclusão dos jovens, que atingiram a idade de ingresso no mercado de trabalho e que, sem perspectiva de emprego, acabam muitas vezes engrossando as fileiras dos trabalhos precários”.

Denota-se, a partir disso, relativa complexidade, que contribui não apenas para a reincidência criminal, mas também para o ingresso de jovens no sistema

Capítulo XXI, art. 56.

Novos Cadernos NAEA • v. 20 n. $1 \cdot$ p. 213-230 • jan-abr 2017 
penitenciário, pois, devido à valorização do consumismo, procuram no crime a forma mais fácil de obterem os bens de consumo estimados pela sociedade. A exigência para inserção ou mesmo permanência do indivíduo no mercado formal exclui muitos que, por falta de oportunidade, sejam elas relacionadas a questões financeiras ou estruturais, não conseguem estar aptos para a grande concorrência de uma vaga no mercado formal, por isso passam a compor outras formas de trabalho, conforme enfatizado por Antunes e Alves (2004, p. 339), que tratam de algumas tendências no mundo do trabalho atual, o chamado 'Terceiro setor', assumindo uma forma alternativa de ocupação, por intermédio de empresas de perfil mais comunitário, abarcando um amplo leque de atividades nas quais predominam aquelas de caráter assistencial. Outra tendência apontada por Antunes e Alves (2004, p. 341), nesta nova conjuntura do trabalho, mesmo que de forma precarizada, refere-se ao "trabalho produtivo doméstico", sendo este "a desconcentração do processo produtivo, pela expansão de pequenas e médias unidades produtivas".

Nesse sentido, inserir-se nesse processo de produção não é tarefa fácil, requer do indivíduo uma busca constante por qualificação, por buscar identificarse com o perfil requerido pelo mercado. É uma questão de sobrevivência, caso não consiga por esses meios legais, sem dúvida vai buscar outros meios para sua subsistência. Ressalta-se não deixar subentendido aqui a visão de justificativa do envolvimento no crime, tendo como motivação sua condição econômico-social.

E, nessa lógica, ao Sistema Penitenciário cabe o dever de preparar o homem encarcerado, quando do término de sua pena, para o mundo do trabalho. Tarefa preconizada na Lei de Execução Penal, que discute sobre um dos grandes desafios para os profissionais que labutam no Cárcere, mas que se torna essencial para o resgate do apenado do mundo do crime, pois, para Bizatto (2005, p.111), “... o trabalho prisional, assim, além de se mostrar um excelente meio de ressocialização só traz benefícios ao apenado. Para o próprio apenado, pode-se destacar a possibilidade de profissionalização e, por consequência, a reintegração ou iniciação ao mercado de trabalho".

As políticas de reinserção social instituídas no Brasil seguem especialmente duas diretrizes, uma da Lei de Execução Penal/LEP³ e Outra do Conselho Nacional de Políticas Criminais e Penitenciaria ${ }^{4}$. Na LEP, encontramos algumas diretrizes, especialmente no que diz respeito à questão laborativa no cárcere,

3 LEI DE EXECUÇÃO PENAL: LEI N. ${ }^{0}$ 7.210, DE JULHO DE 1984, responsável por normatizar a execução penal no país.

4 Com sede em Brasília, subordinado ao Ministério da Justiça e Instalado em junho de 1980, executa planos nacionais de desenvolvimento quanto às metas e prioridades da politica a ser executada. 
pois, conforme especificado por Moreira (2007, p. 258), "o trabalho se expressa como uma via de ressocialização, visto que ao trabalho estão associados valores sociais relacionados à família, à responsabilidade social, e à integridade moral". O trabalho, complementa ele, “[...] configura-se, também, como um elemento valorativo que compõe a identidade do 'homem digno', em oposição ao 'homem indigno', do 'trabalhador' em oposição ao 'criminoso"' (MOREIRA 2007, p. 257).

As diretrizes do Conselho Nacional de Políticas Criminais e Penitenciarias $^{5}$, quando trata do trabalho no cárcere, enfatizam que este não deverá ter caráter aflitivo; ao condenado será garantido trabalho remunerado conforme sua aptidão e condição pessoal, respeitada a determinação médica; será proporcionado ao condenado trabalho educativo e produtivo; devem ser consideradas as necessidades futuras do condenado, bem como as oportunidades oferecidas pelo mercado de trabalho; nos estabelecimentos prisionais devem ser tomadas as mesmas precauções prescritas para proteger a segurança e a saúde dos trabalhadores livres; serão tomadas medidas para indenizar os presos por acidentes de trabalho e doenças profissionais, em condições semelhantes às que a lei dispõe para os trabalhadores livres; a lei ou regulamento fixará a jornada de trabalho diária e semanal para os condenados, observada a destinação de tempo para lazer, descanso. Educação e outras atividades que se exigem como parte do tratamento e com vistas à reinserção social; a remuneração aos condenados deverá possibilitar a indenização pelos danos causados pelo crime, aquisição de objetos de uso pessoal, ajuda à família, constituição de pecúlio que lhe será entregue quando colocado em liberdade.

E ainda ressalta que em lei ou regulamento será fixada jornada de trabalho diária e semanal para os condenados, observada a destinação de tempo para lazer e descanso. A remuneração aos condenados deverá possibilitar a indenização pelos danos causados pelo crime, aquisição de objetos de uso pessoal, ajuda à família, constituição de pecúlio que lhe será entregue quando colocado em liberdade.

Dessa forma, alguns estudos têm buscado pesquisar sobre a efetividade de ações de reinserção social no cárcere e seus resultados quando do cumprimento de pena pelos presos de justiça. Em pesquisa realizada por Elionaldo Julião para sua tese de doutoramento, defendida em 2009, no Rio de Janeiro, detectou-se que, "enquanto o estudo no cárcere diminui a probabilidade de reincidência em 39\%, o trabalho na prisão diminui essas chances em 48\%” (JULIÃO, 2011, p. 151).

Ver Resolução n. ${ }^{\circ} 14$ de 11 de Novembro de 1994, que Trata das Regras Mínimas para Tratamento do Preso no Brasil, e Resolução no 03 de 11 de Março de 2009, que dispõe sobre as Diretrizes Nacionais para a Oferta de Educação nos Estabelecimentos Penais. 


\section{RESULTADOS DA PESQUISA}

Através da pesquisa, identificou-se inicialmente o perfil dos presos participantes do referido projeto, sendo que oito vêm de uma estrutura familiar de pais separados, com baixa escolaridade e cometeram crimes no início da vida adulta. Em relação a processos judiciais, respondem, em sua maioria, por dois processos; tratam-se de processos criminais por roubo, tráfico e homicídio; e são reincidentes.

Já no que diz respeito às suas qualificações profissionais, seguem o perfil dos presos brasileiros e consequentemente paraenses, isto é, não possuem profissões que requerem qualificações técnicas adquiridas através de uma formação específica, pois antes de ingressarem no Sistema Penitenciário tinham como profissão ser ajudante de pedreiro, locutor de loja, lanterneiro, operador de máquinas industriais, marceneiro, operador de plana, eletricista predial, sendo que alguns, mesmo como estas profissões, estavam no trabalho informal, como mototaxista, outros como embalador em mercadinho, entregador de jornal e locutor de loja. Tal realidade pôde ser verificada por Antunes (2009, p. 210): "[...] pode-se constatar de um lado um efetivo processo de intelectualização do trabalho manual; de outro, e em sentido inverso, uma desqualificação e mesmo subproletarização, expressa no trabalho precário, informal, temporário”.

Desse panorama real da vida desses participantes do projeto, antes do ingresso no Sistema Penitenciário, torna-se compreensível o significado do trabalho para eles. A partir das diretrizes apontadas na pesquisa, denota-se a motivação destes em trabalhar no projeto OLIMPO com o intuito de se livrarem antecipadamente do Sistema Penitenciário, já que, a partir da participação em atividade laboral, adquirem o direito da remição de pena, a qual de acordo com o art. 126 da Lei de Execução Penal (LEP), expressa que "o condenado que cumpre pena em regime fechado ou semiaberto poderá remir, pelo trabalho ou por estudo, parte do tempo de execução da pena”, o que, no caso do trabalho, significa que, a cada três dias trabalhados, é diminuído um dia da sentença final. Assim, em linhas gerais, o preso, trabalhando todos os dias durante três anos, terá diminuído de sua pena um ano de prisão.

Outra questão importante observada a partir das falas dos participantes foi o aspecto vantajoso de liberdade ocasionada em razão de participarem do projeto. Neste sentido, eles têm acesso diário ao mundo livre, pois, mesmo sendo conduzidos por transporte da empresa Tramontina, sob supervisão de agentes penitenciários, bem como da empresa, eles conseguem ter acesso ao mundo extramuros, além de terem o sábado para visitar a família, artifício enfatizado 
na fala de um dos detentos que compõem o projeto OLIMPO: "Pelo menos no sábado a gente não fica preso, podemos sair para a casa dos nossos familiares".

Essa condição é dada pela direção da unidade, pois, durante a semana, eles são conduzidos na ida e na volta em veículo específico do projeto, cedido pela empresa Tramontina, sendo que os demais recuperandos de outros projetos saem sozinhos, indo direto para suas atividades, tendo livre arbítrio para, quando possível, passarem pela casa de seus familiares ou irem aonde quiserem.

Dessa forma, a expectativa dos presos como participantes do projeto OLIMPO está voltada para amenizar o sofrimento da prisão, do confinamento, da realidade ociosa vivida pela maioria dos presos no interior da prisão. Este fato foi destacado durante a dinâmica Linha do Tempo, na qual eles deveriam escrever ou desenhar o que eles consideravam ser o motivo que contribuiu para que eles fossem selecionados para o projeto; o que os motivava a permanecer no projeto; e qual era a expectativa destes em relação a trabalho/emprego.

É interessante ressaltar que todos julgaram a condição de terem comportamentos adequados dentro do Sistema Prisional como requisito de seleção para o projeto, além de contarem com a contribuição de uma força divina, como pôde ser analisado nas falas seguintes dos recuperandos participantes da dinâmica:

Por ter um bom comportamento dentro do sistema penal, ter uma boa conduta nas atividades elaboradas no sistema. (Preso por Roubo e Homicídio, participante do projeto há 7 meses).

Acredito que apesar de tantas coisas que aconteceu ainda existem pessoas no meio da sociedade que acreditam na recuperação do detento e são usadas por Deus como canal de benção pra nós e vem a ser mais uma oportunidade. Deus para nós todos. (Preso por Roubo e Homicídio, participante do projeto há 3 meses).

A maioria ressaltou que a motivação em permanecerem no projeto é a saída diária do Sistema Prisional, é o livramento da ociosidade, além do lado bom trazido pelo trabalho, que, incrivelmente, não foi a questão do salário, mas sim do instituto da Lei de Execução Penal, que é a remição da pena, que nitidamente pôde ser vista em uma outra fala de um dos recuperandos:

O motivo que me atrai eu permanecer no projeto é o trabalho e a saída do Sistema todos os dias. (Preso por Roubo e Homicídio, participante do projeto há 3 meses).

Além da saída todos os dias e da remição de pena, foi mencionado também por eles, como motivação, o desejo de mostrarem para a sociedade a mudança após o cárcere. Do grupo, oito falaram sobre isso.

Embora não se tenha percebido muita força no significado de transformação que o trabalho poderia ter para o processo de reinserção social dos apenados, 
pôde ser verificado o desejo de mudança, de sair do mundo do crime e tentar viver uma vida digna, diante dos preceitos impostos pela sociedade, proporcionando, especialmente para seus familiares, um novo direcionamento para suas vidas, após a pena de prisão, conforme proferido por um dos participantes do grupo focal:

Primeiramente a força de Deus e depois o que me motiva é ter uma vida melhor e dar pra minha filha e para minha mãe e também ter uma vida melhor e ter um bom trabalho ou trabalhar na Tramontina e ter a oportunidade de trabalho em qualquer área" (Preso por Tráfico e Homicídio, participante do projeto há 7 meses).

Se irão conseguir, não se sabe, tem-se a certeza de que não será fácil, pois como eles mesmos ressalvaram, ter acrescentado em seu currículo a marca da prisão, é no mínimo, carregar a discriminação, como aspecto negativo, que poderá, independentemente de suas qualificações técnicas, levá-los a uma eliminação em qualquer processo seletivo para emprego, ainda na fase inicial.

Logo, diante dessa perspectiva, foi observado que a expectativa da maioria em relação a trabalho/ emprego após o cumprimento da prisão é ser admitido pela empresa Tramontina. Ao serem questionados sobre isso, pelo menos a metade confirmou este desejo, por terem seu trabalho atualmente reconhecido pela empresa.

Além dessa expectativa, detectou-se que suas grandes aspirações em relação a trabalho/emprego após o cumprimento de pena na prisão voltam-se para a tentativa de sair do mundo do crime, e, através de um trabalho/emprego de carteira assinada, viverem dignamente, mostrando para a sociedade, para seus familiares sua nova opção de vida.

É válido destacar que o desejo de conviverem com a família é muito forte, especialmente de proporcionarem aos seus filhos algo diferente do que eles experimentaram, para que os filhos não percorram os caminhos tortuosos enveredados por eles.

São apresentados, a seguir, alguns relatos sobre as expectativas pós-prisão dos presos nesta etapa da pesquisa:

Trabalhar, ter uma vida de paz. e conquistar os meus objetivos de vida e sair de cabęa erguida vai ser muito bom pra mim e principalmente para minha família, amém e obrigado por mais uma oportunidade. (Preso por Latrocínio, participante do projeto há 7 meses).

A minha expectativa de emprego quando sair do cárcere é trabalhar de carteira assinada e viver uma vida digna, sem problemas. (Preso por Roubo e Homicídio, participante do projeto há 3 meses).

É ser visto como trabalhador e viver feliz com minha familia. (Preso por tráfico de drogas, participante do projeto há 7 meses). 
Embora todos esses anseios tenham sido enfatizados, foi verificado que a palavra trabalho ou o que este pode proporcionar na vida de uma pessoa, no aspecto de qualidade de vida, de bem estar social, ainda é visto como algo, dentro da prisão, que está ligado ao aspecto de remição de pena, de acesso ao mundo exterior à cadeia, oportunidade de estar com a família. Eles não são e nunca foram preparados para uma vida cuja rotina tem como ponto central a labuta para se conseguir suprir todas as necessidades diárias suas e de suas famílias. Ressalta-se o que afirma Moreira (2007, p. 263) ao dizer que "trabalho é concebido como um meio de 'levar' uma vida mais cômoda na penitenciária, ao mesmo tempo em que abrevia a saída da prisão, por meio da remição da pena".

Após a segunda dinâmica algumas questões foram levantadas. A primeira tratou sobre a situação de acreditarem estar sendo produtiva a participação deles no referido projeto, sendo que a maioria respondeu positivamente, complementando que se não estivessem no convênio com a Tramontina estariam na Colônia Penal Agrícola de Santa Izabel em alguma atividade como faxina, na área de suíno, agrícola, ou outras atividades laborais menos interessantes para eles, conforme visualizado por Mesquita (2009, p. 44) que expressa: “daí se justifica a falta de interesse ou até algumas resistências dos presos da Colônia na participação das atividades/projetos existentes, os quais são eminentemente rurais".

Em relação à possibilidade de participarem de outro projeto além do OLIMPO, gostariam de participar de trabalhos voltados para a construção civil. Alguns deram como exemplo a construção de casas populares, outros falaram em estudar, fazer cursos de informática. Poucas ideias foram manifestadas.

Portanto, ressalta-se que, embora em suas falas tenha ficado claro o desejo por mudanças e por se livrarem do cárcere, percebeu-se que a questão do trabalho para os reeducandos não é tão significativa como para os que desde criança vêm sendo motivados para escolher uma profissão. Suas vidas vieram seguindo uma trajetória sem grandes responsabilidades e compromissos, sem possibilidades de alçarem grandes objetivos ou serem profissionais reconhecidos, como se levantou ainda na primeira dinâmica, a qual revelou o baixo grau de escolaridade, suas profissões e últimos trabalhos antes de ingressarem no sistema penitenciário.

\section{CONCLUSÕES}

Diante do exposto, verifica-se que a temática traz relativa complexidade, a partir do momento que levanta discussões divergentes, pelo fato de discutir um assunto polêmico, porém que faz parte da missão do Estado. Essa temática envolve ainda os desafios instituídos à prisão, cuja função diz respeito, ao mesmo 
tempo, a uma instituição de controle social, mas também - mesmo que apenas nos pressupostos normativos - a uma instituição responsável em proporcionar condições harmônicas para a integração social do condenado.

Diante de tal fato, deve-se reconhecer que a prisão não possui estrutura física e funcional para dar conta deste tão almejado desafio por completo. Muito ainda tem a ser feito nesta área para se alcançar, com êxito, os pressupostos preconizados no art. 1. ${ }^{\circ}$ da Lei de Execução Penal.

Quanto aos presos que trabalham no projeto OLIMPO, em linhas gerais, observou-se que não possuem muitas expectativas em relação ao pós-cárcere para atuarem profissionalmente em outras empresas, pois as atividades desenvolvidas por eles são caracterizadas por serviços gerais, não os dotando de capacidade técnica que contribua para uma formação profissionalizante. A partir das falas e comportamentos dos presos envolvidos no referido projeto, notou-se que a palavra "trabalho no interior do cárcere" é sinônimo de "remição de pena". Porém, é válido destacar que, dessa experiência inovadora no Estado do Pará, obtiveramse resultados benéficos: os presos se tornaram mais disciplinados, organizados, respeitosos em relação ao colega, bem como adquiriram espírito de equipe.

Dessa forma, o que se propõe é que, junto com a oportunidade de trabalho, seja proporcionada qualificação profissional relacionada com a educação formal, assim como cursos profissionalizantes condizentes com as demandas de mercado e com as respectivas aptidões e habilidades. Ações motivacionais e informacionais voltadas para atividades laborais também precisam ser efetivadas, bem como palestras que despertem nos presos as percepções sobre suas respectivas habilidades profissionais, pois muitos encontram-se totalmente perdidos, sem noção alguma de qualquer atividade que possam desenvolver para ganhar o sustento sem envolvimento com a criminalidade e o dinheiro fácil.

É necessário que haja um engajamento maior por parte do Sistema Penitenciário, através da realização de uma pesquisa anual diretamente efetivada com os presos, para que possam conhecer, além do perfil destes, suas reais necessidades em relação às ações de reinserção social, no que diz respeito à oferta de educação e trabalho no cárcere, de modo a melhor atender suas expectativas e assim ter um resultado mais efetivo da reinserção destes no mercado de trabalho, mesmo que seja no mercado informal.

Nessa perspectiva, é interessante também que desde seu ingresso no sistema penitenciário sejam disponibilizadas e garantidas pelo Estado atividades educativas voltadas para uma formação profissionalizante, com abordagens de temas transversais direcionadas para a conscientização sobre o trabalho, sua importância, suas formas, bem como para as dificuldades a serem enfrentadas após a pena de prisão. 
Para concluir, em relação à mão de obra carcerária, é interessante que seja garantida sua valorização, através de aspectos e condições dignas no ambiente de trabalho, com salários adequados às atividades desenvolvidas, que não sejam discriminados por sua condição, além de obterem os mesmos direitos e privilégios dados aos funcionários da empresa.

\section{REFERÊNCIAS}

ANTUNES, R. Os sentidos do trabalho: ensaio sobre a afirmação e a negação do trabalho. 2. ed., 10. Reimpr. rev. e ampl. São Paulo: Boitempo, 2009.

ANTUNES, R.; ALVES, G. As mutações no mundo do trabalho na era da mundialização do capital. Educ. Soc., Campinas, v. 25, n. 87, p. 335-351, maio/ ago. 2004.

BARP, W. , NUMMER, F. V. Janela para o mundo: a TV no cárcere feminino em Belém. Belém, Novos Cadernos NAEA, vol. 18, n. 3, 2015, pp.251-270.

BIZATTO, F. A. C. A Pena Privativa de Liberdade e a Ressocialização do Apenado: uma reavaliação das políticas existentes no sistema prisional. 2005. Dissertação (Mestrado em Gestão de Politicas Públicas) - Universidade do Vale do Itajaí.

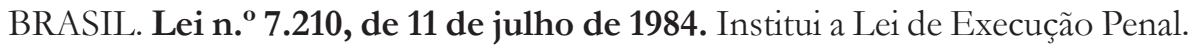
Diário Oficial. Brasília, 11 de julho de 1984.

CABRAL, L. R.; SILVA, J. L. O trabalho penitenciário e a ressocialização do preso no Brasil. Revista do CAAP, Belo Horizonte, v.1, jan-jun 2010.

CAVALCANTE JUNIOR, A. de F. Sociedade do Cárcere: A inversão de uma ordem e a intervenção dos dispositivos de poder-saber numa instituição penal da região Metropolitana de Belém. 2004. Dissertação (Mestrado em Ciências Sociais) - Universidade Federal do Pará,

GOFFMAN, E. Manicômios, prisões e conventos. 7. ed. São Paulo: Editora Perspectiva, 2001.

JULIAO, E. F. A Ressocialização por meio do estudo e do trabalho no sistema penitenciário brasileiro. Revista em Aberto, Brasília, V. 89, p. 141-155, nov. 2011.

KRAHN, N. M. W. Ressocializando - Os Quatro Braços de Shiva: Políticas Laborativas e Educacionais na Prisão. Encontro de Ciências Sociais do Norte e Nordeste, 15, Anais, 2012. 
MELO, J. S. M. et al. Atuação da equipe interdisciplinar da defensoria pública do Estado do Pará nas casas penais: um relato de experiência. Belém: Defensoria Pública do Estado do Pará, v. 1, n.1, jan./jun.2014.

MELOSSI, D.; PAVARINI, M. Cárcere e Fábrica: as origens do sistema penitenciário (sec. XVI a XIX). Rio de Janeiro: Revan: ICC, 2006.

MESQUITA, M. S. Ressocialização: uma experiência na Superintendência do Sistema Penitenciário do Estado do Pará - SUSIPE - Colônia Agrícola Penal Heleno Fragoso. 2009. Monografia (Especialização em Defesa Social e Cidadania) - Universidade do Estado do Pará.

MOREIRA, H. L. F. Trabalho, códigos, gratidão e reciprocidade na prisão: um estudo de caso na Penitenciária de Parnamirim, no Estado do Rio Grande do Norte. 2007. Tese (Doutorado em Ciências Sociais) - Universidade Federal do Pará.

NUNES. L. V. de O. A Ressocialização do preso no município de Paragominas: uma abordagem jurídica. 2012. Monografia (graduação do curso de Bacharel em Direito) - Faculdade Integrada Brasil Amazônia.

SALLA, F. As rebeliões nas prisões: novos significados a partir da experiência brasileira. Sociologias, Porto Alegre, ano 8, n. ${ }^{\circ}$ 16, jul/dez 2006, p. 274-307.

SANTANA, A. P. P. A Casa dos Dias: A Vida no Cárcere Feminino. 2012. Tese (Doutorado em Ciências Sociais). Belém/Pará: Universidade Federal do Pará.

SANTOS, J. G. Reintegração Social do Preso - Utopia e Realidade. Revista CEJ, Brasília, n. 15, pp. 30-45, set./dez. 2001.

THOMPSON, A. A questão penitenciária. 5. ed. Rio de Janeiro: Forense, 2002. WACQUANT, L. As Prisões da Miséria. Tradução: André Telles. Digitalização: 2004. Ed. Sabotagem: 1999. 